\title{
ЛЕПТОТРИХОЗ РОТОВОЙ ПОЛОСТИ: СОВРЕМЕННЫЕ АСПЕКТЫ КЛИНИЧЕСКОГО ТЕЧЕНИЯ И ПРИНЦИПЫ ЛЕЧЕНИЯ
}

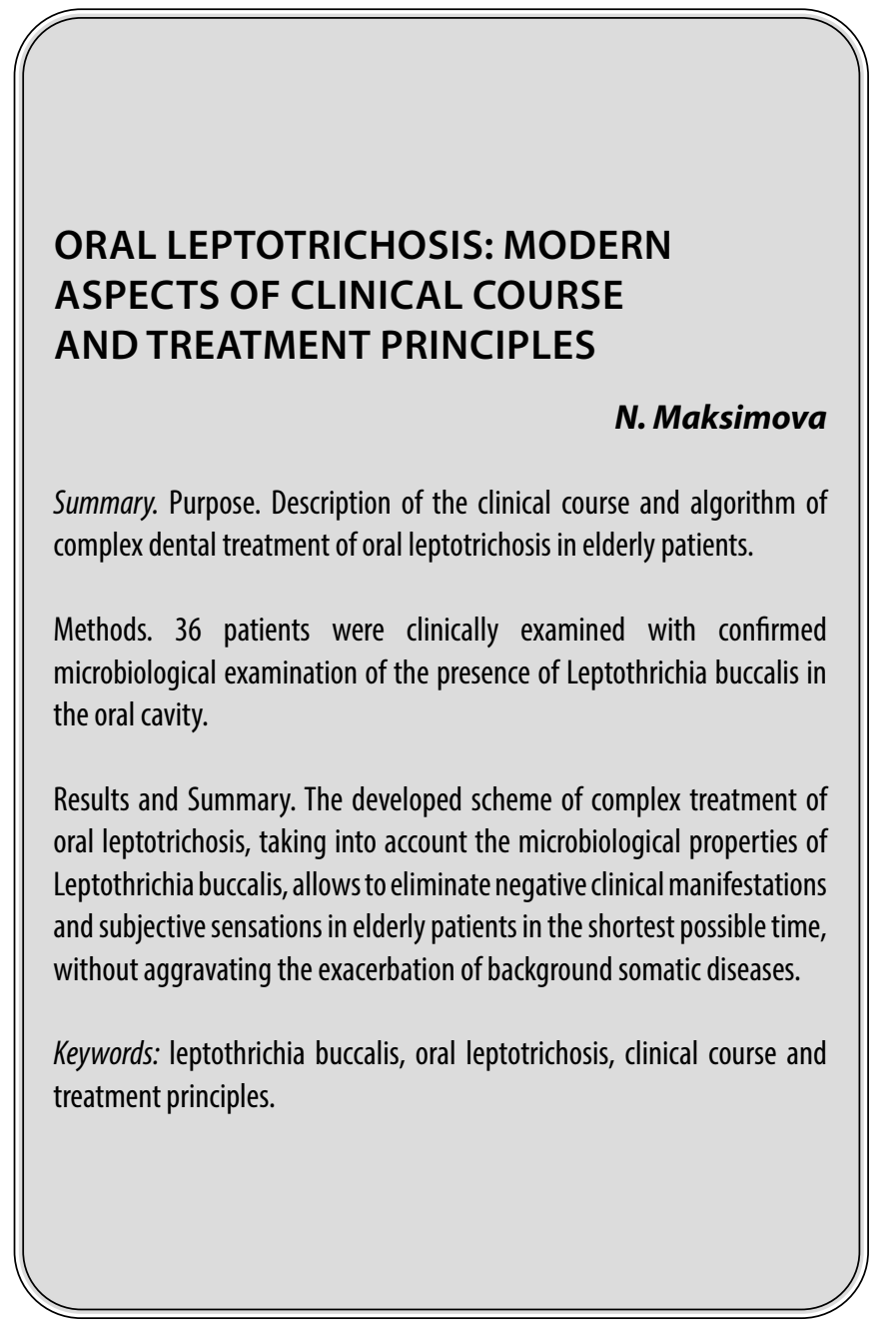

и нтерес к изучению лептотрихоза ротовой полости связан со значительно возросшим количеством пациентов, обращающихся на стоматологический приём с жалобами на сильное нестерпимое чувство жжения полости рта. Прежде всего, следует отметить, что жалобы подобного характера указывают на значительную схожесть клинических проявлений при наличии грибковых инфекции, на связь с заболеваниями различных органов и систем организма, нарушениями обменных процессов, изменениями иммунного статуса и нервно-эндокринной системы.

Особое место среди заболеваний слизистой оболочки рта занимает лептотрихоз в связи с трудностью диагностики заболевания, жалобами как субъективного, так и объективного характера. В настоящие время лепто-
Максимова Наталья Владимировна

ФГБОУ ВО «Рязанский медицинский университет имени академика И. П. Павлова» Министерства здравоохранения Российской Федерачии (г. Рязань) natali2411@bk.ru

Аннотация. Цель. Описание клинического течения и алгоритма комплексного стоматологического лечения лептотрихоза ротовой полости у пациентов пожилого возраста.

Методы. Клинически обследованы 36 пациентов с подтвержденным микробиологическим исследованием наличием Leptothrichia buccalis в ротовой полости.

Результаты и выводы. Разработанная схема комплексного лечения лептотрихоза ротовой полости сучетом микробиологических свойств Leptothrichia buccalis позволяет в минимальные сроки устранить негативные клинические проявления и субъективные ощущения у пациентов пожилого возраста, не усугубив при этом обострение фоновых соматических заболеваний.

Ключевые слова: лептотрихия буккалис, лептотрихоз ротовой полости, клиника, тактика лечения. трихоз, вызываемый сапрофитом полости рта бактерией Leptotrix buccalis, отнесен к псевдомикотическим - вторичным поражениям слизистой $[1,3]$.

Клинически заболевание активно проявляется при снижении резистентности организма на фоне ряда заболеваний слизистой ротоглотки и ЖКТ[4]. По данным ряда авторов, лептотрихоз относят к ВИЧ-ассоциированным заболеваниям $[1,4,5]$.

Согласно микробиологическим исследованиям, лептотрихия (Leptotrichia) (от «leptos» - тонкие + «thrix» - волосы) пердставляет собой анаэробную грамотрицательную бактерию, относящуюся к семейству Fusobacteriaceae. Бактерия образует тонкие нити или «цепочки» (трихии) с сегментированными концами 
и утолщением в центре диаметром 0,2-0,4 мкм, которые не ветвятся и не почкуются. Основываясь на том, что данная бактерия занимает промежуточное положение между бактериями и грибами, то зачастую клинически проявляется как псевдомикотическое поражение. По своим морфологическим данным, а также составу клеточной стенки и антигенной структуре Leptotrichia buccalis, является составной частью условно-патогенной (сапрофитной) микрофлоры полости рта. Излюбленной её локализацией служат складки слизистой оболочки, десневые карманы, ретромолярное пространство, очень много ее обнаруживается среди нитевидных сосочков языка. Установлено, что эта бактерия, являющаяся сапрофитом, способна вызывать патологические изменения в тканях миндалин, размножаясь в криптах, на языке, передней и задней дужках мягкого неба, трахеи, глазах, в тканях пародонта [2]. На фоне ряда заболеваний слизистой ротоглотки и ЖКТ, при снижении резистентности и нарушениях нервно-психологического фона организма человека, лептотрихия клинически манифестирует. Патогенность фузобактерий рода Leptotrichia значительно возрастает в случае их симбиоза с пиогенными кокками - стрептококками и стафилококками.

Лептотрихоз ротовой полости отличается длительным хроническим течением от нескольких месяцев до нескольких лет и значительной устойчивостью к различным способам лечения.

Тяжесть клинического течения и склонность к рецидивам обуславливает необходимость поиска эффективных методов и средств лечения данной патологии.

\section{Шель $\Delta$ аной работы}

Описание клинического течения и схемы комплексного лечения лептотрихоза ротовой полости у пациентов пожилого возраста.

\section{Материал и метолы исслеАования}

Участниками клинического исследования явились 36 пациентов пожилого возраста от 60 до 74 лет, у которых по данным микробиологического исследования была обнаружена в соскобе из ротовой полости анаэробная грамотрицательная бактерия Leptothrichia buccalis и поставлен диагноз Лептотрихоз ротовой полости. Из 36 пациентов - 28 (77,8\%) женщин и 8 мужчин (22,2\%). Клиническое исследование проводилось на базе стоматологической клиники ООО «Прайм-стоматология» г. Рязани. При обращении в клинику все пациенты предъявляли жалобы на нестерпимое чувство жжения во рту, на языке, со стороны слизистой оболочки губ, а также жжение твердого и мягкого нёба. Кроме жалоб на жжение во рту, у 26 (72,2\%) пациентов жаловались на першение в горле, ощущение инородного тела и кома в горле, выраженную сухость в горле, особенно по утрам и наличие пенистой вязкой слюны. Хочется отметить, что со слов пациентов, данные жалобы беспокоили их довольно длительное время, от 3-х и более месяцев и консервативное лечение, назначаемое врачами общего профиля (противогрибковые препараты, рассасывание лизобакта и имудона) оказывалось безуспешным. Пациенты также сообщали, что при возникновении сильного чувства жжения и ощущения горящего рта у них появились нервозность, тревожность, бессонница, канцерофобия.

С целью диагностики возбудителя, учитывая общность жалоб и симптомов, наблюдаемых также при кандидозе ротовой полости, до назначения лечения все пациенты были направлены в ГБУ РО «Областной клинический кожно-венерологический диспансер» г. Рязани на проведение микробиологического исследования - соскоб с языка на Candida albicans и Leptothrichia buccalis. В целях исключения патологических состояний со стороны кровеносной системы - железодефицитная анемия и B-12 дефицитная анемия, которые также проявляются чувством жжения языка, пациенты были дополнительно направлены на общий анализ крови. Пациентам также было проведено общеклиническое стоматологическое обследование.

Всеми участниками исследования были подписаны информированные добровольные согласия на участие в исследовании и на проведение комплексного обследования и лечения.

Таким образом, критериями включения пациентов в исследование стали:

1. пациенты пожилого возраста от 60 до 74 лет;

2. жалобы при обращении на стоматологический приём: на сильное чувство жжения во рту, на языке, со стороны слизистой оболочки губ, твердого и мягкого нёба, на першение в горле, ощущение инородного тела и кома в горле, выраженную сухость в горле, особенно по утрам и наличие пенистой вязкой слюны;

3. наличие фоновых соматических заболеваний в стадии ремиссии или компенсации;

4. обнаружение при микробиологическом исследовании патогенной грамотрицательной анаэробной бактерии - Leptothrichia buccalis

5. безуспешность ранее проводимого лечения

\section{Результаты исслеАования.}

По результатам клинического осмотра у 36 пациентов видимых воспалительных явлений на слизистой оболочке не визуализировалось, однако у всех выявлена: слабоувлажненная слизистая оболочка, в области 
корня языка густой, вязкий слизистый секрет, язык с небольшим количеством беловатого налета. Нитевидные и листовидные соссочки наблюдались незначительно увеличенными у 5 пациентов (13,9\%) и у 24 пациентов были гипертрофированы желобоватые сосочки языка. При получении результатов микробиологического исследования пациентам назначалось лечение, учитывая микробиологические характеристики патогенной неспорообразующей анаэробной грамотрицательной бактерии Leptothrihia buccalis, и корректировалось в соответствие с жалобами, состоянием полости рта пациентов, состоянием организма в целом. На этапе коммуникации с пациентом и объяснении плана лечения всем пациентам было разъяснено, что комплексное лечение лептотрихоза как ротовой полости, так и фарингеальной области занимает около 6-8 месяцев с периодически возникающими рецидивами заболевания. Комплексное лечение заключалось в назначении общего и местного лечения.

Общее лечение в первую очередь заключалось проведение антибактериальной терапии. Однако известно, что данная бактерия, обладает высокой устойчивостью к большинству видов антибактериальных препаратов, таких как макролиды, аминогликозиды, фторхинолоны, но остается чувствительной к метронидазолу, клиндамицину, левомицетину. Безусловно, для устранения данного патогена обязательным условием является назначение одного из вышеуказанных лекарственных препаратов, но учитывая возраст больных, а также наличие фоновых соматических заболеваний, не хотелось вызвать или усилить дисбактериоз кишечника и усугубить тем самым фоновую патологию, в связи с этим, было принято решение воздействовать на данную патогенную бактерию местно, назначив раствор «Метрогил» в виде полоскания рта 3 раза в день по 3-5 минут после приема пищи в течение 7 дней. Для снижения аллергизации организма необходимым является назначение десенсибилизирующих препаратов 2-3 поколения, курсом 14 дней. Учитывая длительность болезненного состояния пациентов, вызванного патогенной бактерией и появление неврастенических симптомов - нервозности, тревожности, бессонницы, канцерофобии, возникает необходимость в назначении дневных транквилизаторов с седативным эффектом. Учитывая возраст больных, препаратом выбора стал «Афобазол», назначаемый по 1 таблетке 2-3 раза в день в течение 30 дней. В процессе тщательного сбора анамнеза установлено, что у всех больных данное состояние возникло в результате какого-либо перенесенного стресса, нервного перенапряжения или состояния дискомфорта (дисбактериоза) в кишечнике, пациентам было рекомендовано пройти курс пробиотиков с целью коррекции состава кишечной микрофлоры для улучшения работы пищеварительного тракта и нормализации работы кишечника.
Местное лечение назначалось также с учетом микробиологических характеристик данной бактерии и заключалось, прежде всего полоскании рта раствором, выделяющим кислород - перманганатом калия (слабо розовым раствором) или раствором перекиси водорода 1\% 3-4 раза в день по схеме лечения: 3 недели полоскания и 1 неделя перерыв. Известно, что Leptothrichia buccalis испытывают тропность к лимфоидной ткани и часто локализуются в области язычной миндалины и лакунах глоточной миндалины, вызывая тем самым неприятные ощущения першения в горле, чувство инородного тела, чувство жжения в глотке, поэтому пациентам было рекомендовано полоскание масляным раствором Хлорофиллипта, позволяющего использовать данный препарат при снижении природного иммунитета, в качестве средства борьбы с гипоксией тканей, а также в качестве средства, повышающего эффективность одновременно применяющихся противомикробных препаратов. Учитывая микробиологические свойства Leptothrichia buccalis о том, что идеальные условия для жизни и размножения бактерии температура $35-37^{\circ} \mathrm{C}$, то для нарушения процессов жизнедеятельности бактерии и с целью облегчения сильного чувства жжения во рту, больным была рекомендована гипотермия в виде рассасывания кубиков льда.

Через 1 месяц после назначенного данного курса лечения у 29 (80,5\%) пациентов прекратилось чувство жжения в полости рта и ощущение кома и першения в горле. Однако им было рекомендовано продолжение местного лечения до 3-х месяцев во избежание возникновения рецидивов. У оставшихся 7 пациентов через 1 месяц после лечения сохранялись жалобы на незначительные неприятные ощущения в области горла по утрам и чувство жжения в течение дня, но значительно меньшей интенсивности.

По результатам микробиологического исследования, проведенного через 3 месяца от начала курса лечения у $82 \%$ исследуемых пациентов Leptothrichia buccalis в мазке не выявлена, у оставшихся 18\% пациентов Leptothrichia buccalis обнаружена в мазке, но клиническая симптоматика отсутствовала.

\section{Выво}

Разработанная схема комплексного лечения лептотрихоза ротовой полости с учетом микробиологических свойств Leptothrichia buccalis позволяет в минимальные сроки устранить негативные клинические проявления и субъективные ощущения у пациентов пожилого возраста, не усугубив при этом обострение фоновых соматических заболеваний. Однако следует помнить, что обнаружение лептотрихий при отсутствии симптомов не является показанием к назначению лечения, так как они могут выявляться у здоровых лиц. 


\section{ЛИТЕРАТУРА}

1. Алешин В.А. К диагностике, клинике и лечению лептотрихоза глотки: Автореф. дис. . . . канд.мед. наук. / М 1966. — 42 с.

2. Ариевич А.М., Степанищева 3. Г. // Вестник оториноларингологии. 1964.— № 5.— - $48-53$

3. Загорянская М. Е. Криотерапия лептотрихозного поражения ротоглотки. / сб.: Межобластная научно-практическая конференция оториноларингологов Сибири, Дальнего Востока. 1974.- - С. 154-156.

4. Кунельская В.Я. Клиника и лечение лептотрихоза и кандидоза миндалин. //Вестник оториноларингологии — 1969. — № 5.—C. 105-110.

5. Челидзе Н. Д. Новый метод лечения лептотрихоза ротоглотки. Вестник оториноларингологии, N5-2000, стр. 64-65

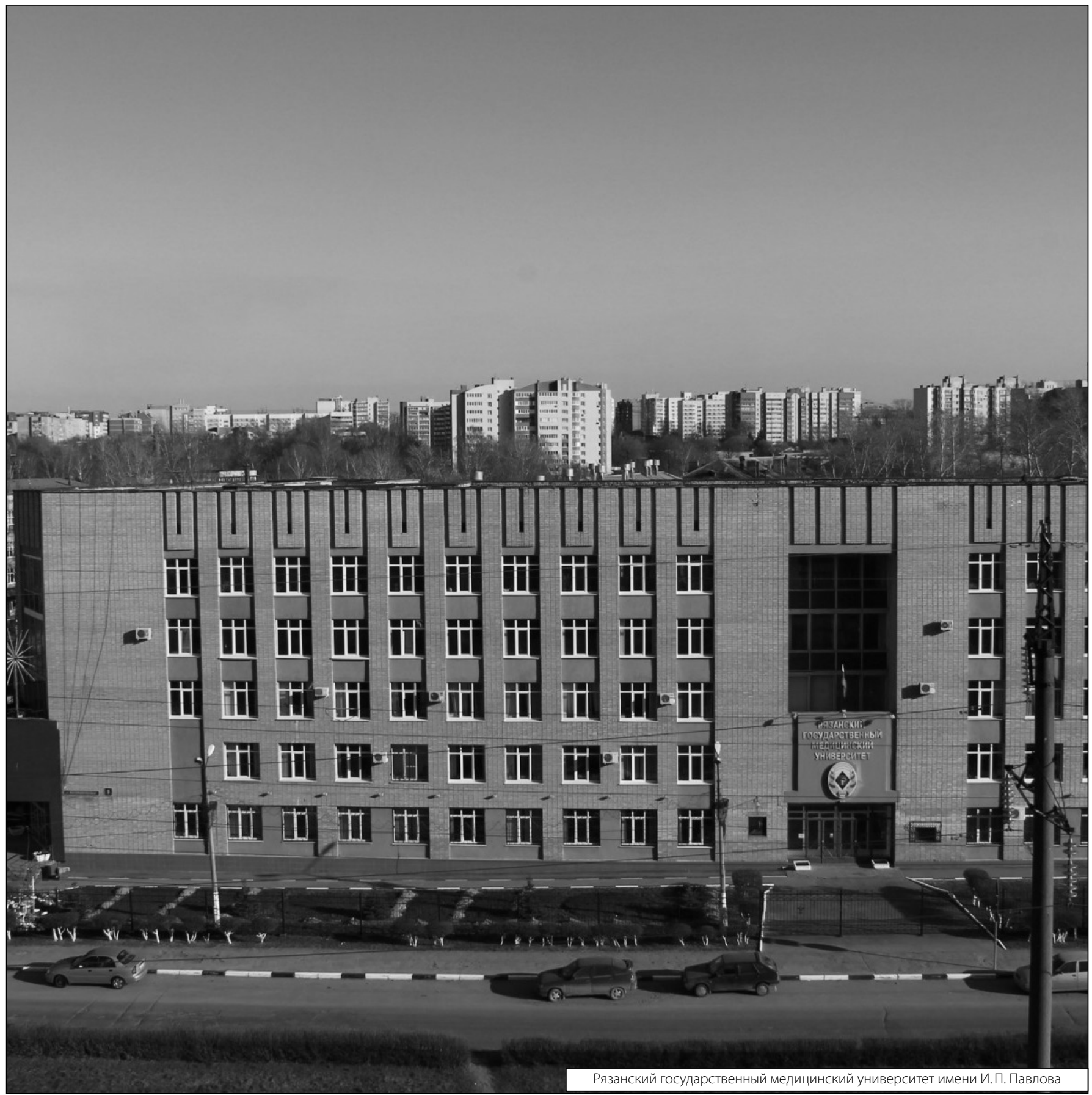

